\title{
PENGARUH PERCEIVED PRICE DAN COUNTRY OF ORIGIN TERHADAP REPURCHASE INTENTION MEREK MINUMAN XING FU TANG DI JAKARTA: WORD OF MOUTH SEBAGAI VARIABEL MEDIASI
}

\author{
Lucas Kevin dan Miharni Tjokrosaputro \\ Fakultas Ekonomi dan Bisinis Universitas Tarumanagara, Jakarta \\ Email: Lucas.115160029@stu.untar.ac.id; miharnit@fe.untar.ac.id
}

\begin{abstract}
The purpose of this research is to examine whether 1) perceived price can effect repurchase intention. 2) perceived price can effect word of mouth. 3) country of origin can effect repurchase intention. 4) word of mouth can effect repurchase intention. 5) word of mouth mediates the effect perceived price on repurchase intention. Sample was selected using convenience sampling method amounted to 200 respondents. The result of this study show that perceived price and country of origin have not significant influence on repurchase intention, perceived price has significant influence on word of mouth, word of mouth has significant influence on repurchase intention, and word of mouth mediates the influence of perceived price on repurchase intention.
\end{abstract}

Keywords: Perceived Price, Country of Origin, Word of Mouth, Repurchase Intention.

Abstrak: Tujuan dari penelitian ini adalah untuk menguji apakah 1) perceived price dapat mempengaruhi repurchase intention. 2) perceived price dapat mempengaruhi word of mouth. 3) country of origin dapat mempengaruhi repurchase intention. 4) word of mouth dapat mempengaruhi repurchase intention. 5) word of mouth memediasi pengaruh perceived price terhadap repurchase intention. Sampel dipilih menggunakan metode convenience sampling berjumlah 200 responden. Hasil dari penelitian ini menunjukkan bahwa perceived price dan country of origin tidak memiliki pengaruh yang signifikan terhadap repurchase intention, perceived price memiliki pengaruh yang signifikan terhadap word of mouth, word of mouth memiliki pengaruh yang signifikan terhadap repurchase intention, dan word of mouth dapat memediasi pengaruh perceived price terhadap repurchase intention.

Kata Kunci: Perceived Price, Country of Origin, Word of Mouth, Repurchase Intention

\section{LATAR BELAKANG}

Indonesia memiliki penduduk yang sangat banyak dan masyarakat di kota-kota besar seperti Jakarta memiliki pola hidup yang sangat konsumtif dan tertarik dengan produk baru. Pada awal tahun 2019 ada jenis minuman baru yang sangat digemari oleh masyarakat di Indonesia dan jenis minuman ini berasal dari Taiwan. Beberapa merek minuman asal Taiwan tersebut masuk ke pasar Indonesia karena melihat potensi pasar yang menjanjikan di Indonesia, tidak terkecuali merek Xing Fu Tang. Merek Xing Fu Tang mendapat sambutan yang sangat baik di Indonesia terbukti dengan pelanggan yang rela antri mulai jam 5 pagi demi mencoba minuman asal Taiwan tersebut (Kumparan, 2019). Dengan begitu besar niat pembelian masyarkat Indonesia terhadap produk Xing Fu Tang maka perusahaan perlu mempertahankan niat pembelian yang ada sehingga konsumen yang sudah pernah mencicipi minuman dari Xing Fu Tang memiliki niat untuk melakukan pembelian kembali produk Xing Fu Tang di masa depan. 
Menurut Hellier dkk. (2003) repurchase intention merupakan keputusan yang terencana dari seseorang untuk melakukan pembelian kembali barang atau jasa yang pernah digunakan, dengan mempertimbangkan situasi yang terjadi dan tingkat kesukaan produk. Berdasarkan penelitian yang sudah pernah dilakukan sebelumnya, ada banyak faktor yang dapat mempengaruhi repurchase intention. Khan dkk. (2012) menyatakan bahwa product perceptions dan service performance memiliki pengaruh yang positif terhadap repurchase intention. Goh dkk. (2016) menjelaskan bahwa consumer inertia, product attribute, dan luxury value memiliki pengaruh yang positif terhadap repurchase intention. Matarazzo (2018) menunjukkan bahwa country of origin dan corporate memiliki kontribusi positif terhadap repurchase intention. Penelitian Moslehpour (2016) menjelaskan bahwa perceived price dan country of origin memiliki pengaruh yang positif terhadap repurchase intention. Moslehpour (2016) juga menyatakan bahwa word of mouth dapat memediasi perceived price dan country of origin terhadap repurchase intention.

\section{KAJIAN TEORI}

Penelitian yang dilakukan mengacu pada theory of planned behavior yang dijelaskan oleh Ajzen (1991). Teori ini menjelaskan faktor pembentukan niat seseorang dalam berperilaku. Dalam teori ini dijelaskan bagaimana sikap yang ada terbentuk berdasarkan hal-hal positif dan negatif yang diterima oleh individu sehingga memunculkan niat untuk berperilaku. Teori ini menunjukkan bagaimana word of mouth dapat mempengaruhi niat pembelian kembali atau repurchase intention seorang konsumen pada suatu merek atau produk. Menurut Latane (1981) dalam proses seorang konsumen melakukan evaluasi terhadap suatu merek, sangat dipengaruhi oleh faktor sosial atau lingkungan sekitar yang memiliki kekuatan untuk mempengaruhi seseorang dalam bersikap. Oleh sebab itu word of mouth berperan penting dalam suatu pemasaran karena dengan adanya word of mouth, setiap konsumen dapat saling berbagi pengalamannya satu dengan yang lain di lingkungan sekitar dan dari setiap pengalaman itu konsumen dapat mengambil keputusan untuk melakukan pembelian kembali atau tidak.

Repurchase Intention. Menurut Goh dkk. (2016:994) repurchase intention adalah "when consumers initiated the effort to purchase the same brand, products or service again". Sedangkan Ibzan dkk. (2016:97) menyatakan repurchase intention adalah "repurchase is described as a real action of customer in buying or using the product again". Menurut Adekunle (2018:795) menjelaskan repurchase intention adalah "repurchase intention is the degree of perceptual conviction of a customer to repurchase a particular product (or service) or to repurchase any product (or service) at a particular organization". Melalui definisi diatas dapat disimpulkan bahwa repurchase intention adalah suatu keyakinan yang dimiliki oleh seorang konsumen terhadap produk atau jasa tertentu sehingga memunculkan tindakan yang nyata untuk melakukan pembelian kembali produk atau jasa yang pernah digunakan.

Perceived Price. Menurut Basil dkk. (2013:142) perceived price adalah "prices can be defined as the nominal value charged to the customer to acquire products and to be benefited from the ownership or use of products". Sedangkan Diallo (2012:361) menjelaskan bahwa "perceived price as the overall representation of the relative level of store brands' prices for a given retailer". Menurut Porral (2017:91) perceived price adalah "perceived price as the consumers' judgement of price the affordability of store brand products". Dari penjelasan berikut, maka dapat disimpulkan perceived price adalah pandangan seseorang terhadap harga suatu produk yang dibebankan kepadanya dan melihat apakah harga tersebut sesuai dengan harga produk lain yang sejenis. 
Country of Origin. Menurut Kholid dkk. (2018:194) menyatakan "country of origin are the mental pictures of brands and countries, respectively". Lebih lanjut menurut Bahrinizadeh dkk. (2014:138) "country of origin refers to information pertaining to where a product is made. It is also defined as the positive or negative influencelassociations that a product's country of manufacture may have on consumers' decision processes or subsequent behavior". Sedangkan menurut Keni (2018:238) country of origin adalah "an important marketing element known to influence consumer perceptions as well as behavior". Dari berbagai definisi yang telah disampaikan diatas, maka dapat diambil kesimpulan country of origin adalah elemen penting dalam suatu merek atau produk untuk menimbulkan kepercayaan seorang konsumen kepada suatu merek atau produk, sehingga dapat mempengaruhi pandangan konsumen terhadap suatu merek.

Word of Mouth. Menurut Moslehpour (2016:572) word of mouth adalah " $a$ way consumers share their thought about the product through informal networks and personal communications". Lebih lanjut, Taghizadeh dkk. (2013:2570) menyatakan bahwa "word of mouth is a powerful marketing factor that received significant emphasis from various service providers, particularly, those whose businesses focus on intangible offerings". Sedangkan Hawkins (2015:235) menjelaskan word of mouth adalah " a key factor that customers tend to rely on before making purchase decisions, and is reflected through the experiences shared by others toward certain products, services, and brands". Melalui definisi diatas dapat diambil kesimpulan bahwa word of mouth adalah salah satu faktor kunci yang sangat menentukan dalam membangun niat beli konsumen, tercermin dari berbagai pengalaman yang telah dilalui oleh orang lain terhadap suatu produk, layanan atau merek tertentu karena pengalaman orang tersebut dapat menjelaskan secara rinci bagaimana kualitas merek atau produk tersebut.

\section{Kaitan antara Perceived Price, Country of Origin dan Repurchase Intention}

Kaitan antara Perceived Price dan Repurchase Intention. Jika suatu produk memiliki harga yang masuk akal dan sesuai dengan kualitasnya maka konsumen akan melakukan pembelian kembali walaupun harga yang ditawarkan tidak murah (Moslehpour, 2016). Harga yang sesuai dengan kualitas produk akan menimbulkan niat pelakukan pembelian kembali (Suhaily, 2017). Persepsi harga bukan merupakan indikator konsumen melakukan pembelian kembali namun kepuasan pelanggan terhadap suatu produk yang akan menimbulkan niat melakukan pembelian kembali (Khan dkk., 2012).

Kaitan antara Perceived Price dan Word of Mouth. Ketika konsumen merasakan harga produk wajar dan memiliki kualitas dan nilai yang baik, mereka cenderung berbagi pendapat mereka dengan teman-teman mereka (Moslehpour, 2016). Saat konsumen puas dengan kesesuaian harga dan kualitas yang ditawarkan maka konsumen akan menyebarkannya dari mulut ke mulut (Tong dkk., 2013). Tingkat kepuasan pelanggan terhadap kesesuaian harga harus dijaga agar memiliki kesempatan sebagai iklan gratis untuk perusahaan (Choo dkk., 2016).

Kaitan antara Country of Origin dan Repurchase Intention. Variabel country of origin tidak berpengaruh terhadap niat beli konsumen karena pengaruh perbedaan dalam demografi responden (Phuong, 2017). Konsumen akan melihat gambar dari kemasan yang dapat mendefinisikan negara asal sebelum membeli produk (Moslehpour, 2016). Semakin kuat country of origin suatu merek maka akan semakin kuat niat pembelian suatu produk (Matarazzo, 2018). 
Kaitan antara Word of Mouth dan Repurchase Intention. Word of mouth merupakan salah satu variabel penting dalam pemasaran karena konsumen lebih percaya dengan apa kata orang lain yang telah menggunakan produk atau jasa tertentu dibanding hanya melihat iklan dari produk atau jasa yang ada, sehingga akan menguatkan niat pembelian kembali (Moslehpour, 2016). Word of mouth memainkan peran yang penting dalam membuat pelanggan mengambil keputusan untuk melakukan pembelian kembali (Saleem, 2017). Word of Mouth merupakan kunci dari niat pembelian kembali suatu produk (Thung, 2017).

Word of Mouth memediasi kaitan antara Perceived Price dan Repurchase Intention. Moslehpour (2016) mengungkapkan bahwa variabel word of mouth memiliki pengaruh terhadap hubungan antara variabel perceived price dan repurchase intention. Word of mouth dapat mempengaruhi repurchase intention secara signifikan dan dapat memberikan landasan yang baik untuk mediasi perceived price terhadap repurchase intention. Hasil penelitian ini adalah word of mouth sebagai variabel mediasi dapat lebih menguatkan pengaruh perceived price terhadap repurchase intention.

Berdasarkan pemaparan di atas, maka model dan hipotesis penelitian yang digunakan dalam penelitian ini adalah sebagai berikut.

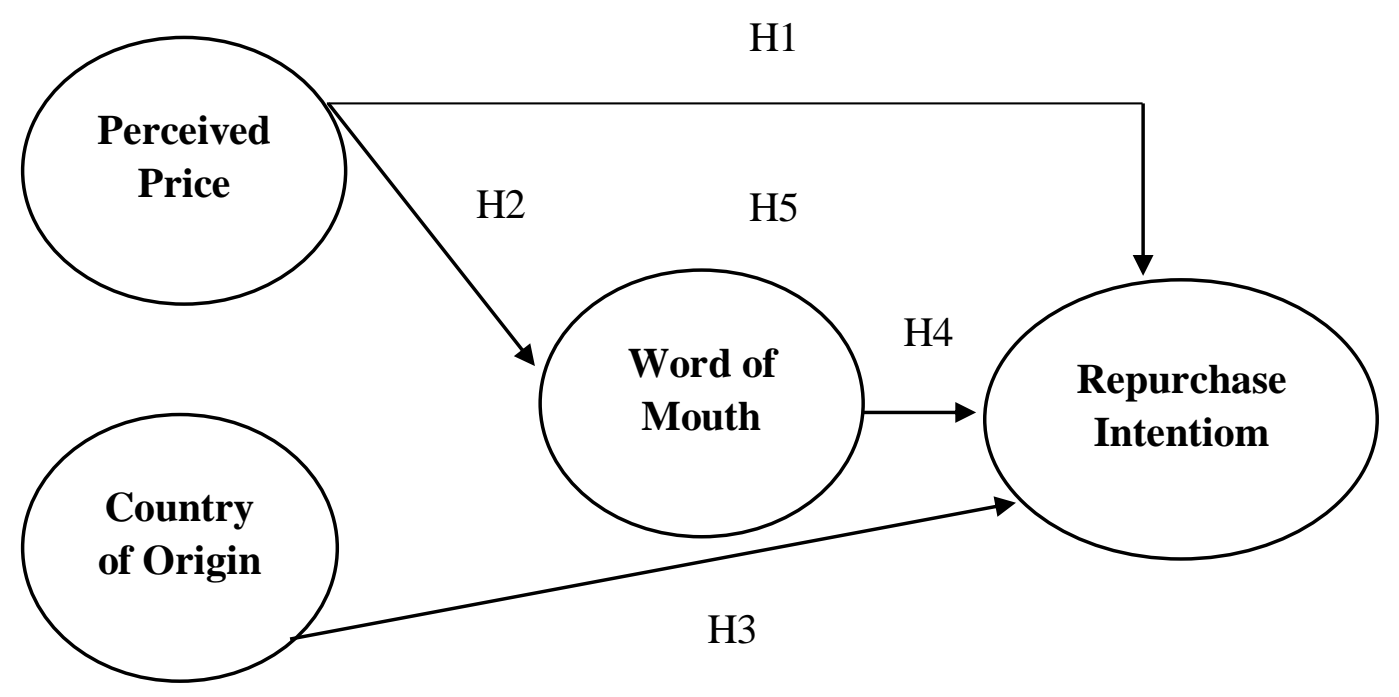

Gambar 1. Model Penelitian

Hipotesis dalam penelitian ini mengacu pada penelitian Moslehpour (2016) dan hipotesis adalah sebagai berikut:

$\mathrm{H}_{1}$ : Perceived price memiliki pengaruh yang positif terhadap repurchase intention merek minuman Xing Fu Tang di Jakarta.

$\mathrm{H}_{2}$ : Perceived price memiliki pengaruh yang positif terhadap word of mouth merek minuman Xing Fu Tang di Jakarta.

$\mathrm{H}_{3}$ : Country of origin memiliki pengaruh yang positif tehadap repurchase intention merek minuman Xing Fu Tang di Jakarta.

$\mathrm{H}_{4}$ : Word of mouth memiliki pengaruh yang positif terhadap repurchase intention merek minuman Xing Fu Tang di Jakarta.

$\mathrm{H}_{5}$ : Word of mouth dapat memediasi perceived price terhadap repurchase intention merek minuman Xing Fu Tang di Jakarta.

\section{METODOLOGI}


Pada penelitian kali ini jenis penelitian yang dipakai peneliti adalah penelitian deskriptif cross sectional. Populasi dalam penelitian ini adalah masyarakat Jakarta yang mengetahui dan sudah pernah membeli minuman Xing Fu tang. Sampel yang diambil menggunakan teknik non probability sampling, dengan menggunakan metode convenience sampling. Teknik tersebut digunakan agar dapat mengumpulkan secara mudah dan cepat. Jumlah responden yang diteliti dalam penelitian ini sebanyak 200 responden.

Pengukuran variabel-variabel dibawah ini mengacu pada penelitian yang sudah dilakukan sebelumnya antara lain sebagai berikut:

\begin{tabular}{ccc} 
Variabel & Indikator & Acuan \\
\hline Repurchase Intention & 4 item & $\begin{array}{c}\text { Chou dan Chen (2018), Kim } \\
\text { dkk (2012) }\end{array}$ \\
\hline Perceived Price & 5 item & $\begin{array}{c}\text { Ebrahim dkk (2016), Afsar } \\
\text { (2014), Suhud (2019), dan } \\
\text { Oosthuizen dkk (2015) }\end{array}$ \\
\hline Country of Origin & 5 item & Jimenez (2014) \\
\hline Word of Mouth & 5 item & Maisam (2016) dan Pollack \\
(2017
\end{tabular}

Dalam penelitian ini metode yang digunakan untuk mengumpulkan data dari responden adalah dengan menggunakan kuesioner. Penelitian ini menggunakan skala interval dalam mengukur jawaban dari responden dalam bentuk skala Likert. Dalam menguji variabel pada penelitian ini, skala Likert yang digunakan adalah skala satu sampai dengan lima. Angka satu berarti sangat tidak setuju, angka dua tidak setuju, angka tiga netral, angka empat setuju dan angka lima sangat setuju.

\section{HASIL UJI STATISTIK}

Hasil uji validitas pada penelitian ini dapat dikatakan valid apabila nilai AVE yang didapatkan memiliki nilai diatas 0,5 dan nilai loading factor dari setiap indikatornya memiliki nilai diatas 0,7 . Hasil uji reliabilitas pada penelitian ini dapat dikatakan reliabel dengan menganalisis nilai cronbach's alpha dan composite reliability. Dapat dikatakan reliabel jika nilai pada cronbach's alpha lebih besar dari 0,6. Sedangkan nilai composite reliability dapat diterima jika nilainya diatas 0,7 .

$\mathrm{R}^{2}$ digunakan untuk mengukur seberapa besar variabel perceived price, country of origin, dan word of mouth dapat menjelaskan variabel repurchase intention. Pada penelitian ini nilai 0,701 yang bisa diartikan bahwa sebesar $70,1 \%$ variabel repurchase intention dapat dijelaskan oleh variabel-variabel yang ada dalam penelitian ini. Lalu sisanya sebesar 29,9\% dapat dijelaskan oleh variabel-variabel yang tidak ada dalam penelitian kali ini. Nilai R-square variabel mediasi dalam penelitian ini sebesar 0.342 yang bisa diartikan bahwa sebesar 34,2\% variabel word of mouth yang merupakan variabel mediasi dalam penelitian ini dapat dijelaskan oleh variabel-variabel yang ada dalam penelitian ini. Sisanya sebesar 65,8\% dapat dijelaskan oleh variabel-variabel yang tidak ada dalam penelitian ini. Selanjutnya hasil pengujian $\mathrm{Q}^{2}$ menunjukan nilai sebesar 0,282 word of mouth dan 0,504 untuk repurchase intention yang artinya nilai predictive relevance dalam penelitian ini lebih besar dari 0 (nol).

Hasil analisis data secara singkat dapat dilihat pada Tabel 1.

Tabel 1. Hasil Pengujian Hipotesis 


\begin{tabular}{cccc}
\hline Variabel & Path Coefficient & t-statistics & p-values \\
\hline $\begin{array}{c}\text { Perceived price }=>\text { Repurchase } \\
\text { Intention }\end{array}$ & 0,122 & 1,892 & 0,059 \\
\hline $\begin{array}{c}\text { Perceived Price }=>\text { Word of Mouth } \\
\text { Country of Origin => Repurchase }\end{array}$ & 0,585 & 9,665 & 0,000 \\
\hline $\begin{array}{c}\text { Word of Mouth }=>\text { Repurchase } \\
\text { Intention }\end{array}$ & 0,064 & 1,118 & 0,264 \\
\hline $\begin{array}{c}\text { Perceived Price }=>\text { Word of Mouth }=> \\
\text { Repurchase Intention }\end{array}$ & 0,718 & 11,134 & 0,021 \\
\hline
\end{tabular}

Pengujian lain dalam penelitian ini dapat dilihat dari nilai effect size. Hasil effect size dalam penelitian ini menunjukkan variabel country of origin terhadap variabel repurchase intention tidak memiliki pengaruh karena memiliki nilai effect size dibawah standar yaitu sebesar 0.008 . Selanjutnya variabel perceived price memiliki pengaruh yang kecil terhadap variabel repurchase intention karena hanya memiliki nilai sebesar 0.029 , lebih dari nilai minimal effect size 0.02. Yang ketiga ada hubungan antara variabel word of mouth terhadap repurchase intention, word of mouth memiliki efek yang besar terhadap repurchase intention karena memiliki nilai effect size melebihi 0.35 yaitu sebesar 0.947. Yang terakhir ada variabel perceived price terhadap word of mouth yang memiliki efek besar terhadap variabel word of mouth karena memiliki nilai melebihi 0.35 yaitu sebesar 0.521 . Berikutnya ada pengujian Goodness of Fit yang memiliki hasil sebesar 0,6032. Nilai Goodness of Fit dianggap tinggi apabila berada pada nilai diatas 0,36 (Ghozali dan Latan, 2015).

\section{DISKUSI}

Berdasarkan hasil pengujian hipotesis pertama $\left(\mathrm{H}_{1}\right)$, diketahui bahwa variabel perceived price tidak memiliki pengaruh yang positif terhadap variabel repurchase intention. Hasil penelitian ini tidak sesuai dengan penelitian Moslehpour (2016), tapi mendapat dukungan dari penelitian Khan dkk. (2012). Hal yang terjadi dalam penelitian Khan dkk. (2012) kemungkinan juga dialami oleh para pelanggan Xing Fu Tang yang merasa kepuasan pelanggan lebih penting dibanding perceived price dalam menimbulkan minat melakukan pembelian kembali. Walaupun menempatkan produknya sebagai produk yang memiliki nilai lebih, itu tidak membuat konsumen ingin melakukan pembelian kembali dikarenakan perceived price bukanlah faktor utama konsumen Xing Fu Tang untuk melakukan pembelian kembali produknya. Dari hasil penelitian ini dapat dilihat jika mayoritas pembeli minuman merek Xing Fu Tang yang ada di Jakarta tidak melihat perceived price sebagai faktor penting dalam memutuskan untuk melakukan pembelian kembali.

Hasil pengujian pada hipotesis kedua $\left(\mathrm{H}_{2}\right)$ menunjukkan bahwa perceived price dapat memprediksi secara positif word of mouth merek minuman Xing Fu Tang di Jakarta, sehingga dapat dikatakan bahwa hipotesis tidak ditolak. Hasil penelitian tersebut sejalan dengan penelitian yang dilakukan oleh Tong dkk. (2013) dan Choo dkk. (2016). Apabila saat konsumen membeli produk Xing Fu Tang dan konsumennya merasa terjadi kesesuaian antara harga dengan kualitas produk maka akan terjadi kepuasan pelanggan yang menyebabkan pelanggan tersebut akan membagikan pengalamannya. Dalam dunia bisnis word of mouth 
adalah hal yang sangat penting karena merupakan sesuatu yang dibutuhkan untuk membangun kepercayaan konsumen terhadap suatu merek.

Selanjutnya hasil pengujian hipotesis ketiga $\left(\mathrm{H}_{3}\right)$ menunjukkan bahwa country of origin tidak dapat memprediksi secara positif repurchase intention merek minuman Xing Fu Tang di Jakarta, maka bisa disimpulkan jika hipotesis ketiga ditolak. Hasil penelitian ini tidak sesuai dengan penelitian Moslehpour (2016) dan penelitian Matarazzo (2018). Kedua penelitian tersebut menyatakan bahwa country of origin dapat berkontribusi positif terhadap repurchase intention. Namun hasil penelitian peneliti mendapat dukungan dari penelitian Phuong (2017) yang menyatakan bahwa country of origin tidak memiliki pengaruh yang signfikan terhadap repurchase intention. Apabila nilai orisinalitas minuman Xing Fu Tang cukup diakui oleh pelanggan diluar Taiwan maka konsumen pun akan memiliki niat untuk melakukan pembelian kembali minuman Xing Fu Tang. Tetapi jika rasa yang ditawarkan oleh Xing Fu Tang tidak begitu spesial bagi pelanggan maka pelanggan dapat memilih alternatif produk dan tidak memiliki niat melakukan pembelian kembali terhadap produk Xing Fu Tang.

Hasil pengujian hipotesis keempat $\left(\mathrm{H}_{4}\right)$ menunjukkan bahwa word of mouth dapat memprediksi secara positif repurchase intention merek minuman Xing Fu Tang di Jakarta. Hasil penelitan ini sesuai dengan penelitian Moslehpour (2016), Saleem (2017), dan Thung (2017). Ketiga penelitian tersebut seepakat bahwa word of mouth memiliki pengaruh yang positif terhadap repurchase intention. Word of mouth adalah salah satu kunci yang sangat penting bagi suatu produk untuk mempertahankan pelanggannya atau menjaga produknya dibeli oleh para konsumen. Apabila perusahaan tidak mampu untuk menjaga kualitasnya maka konsumen akan menilai produk tersebut kurang baik dan dapat mengakibatkan konsumen menyebarkan informasi tentang kualitas produk yang dipakai kepada konsumen lain. Seperti yang dijelaskan oleh Moslehpour (2016), konsumen lebih percaya dengan apa kata orang lain dibanding dengan melihat iklan produk atau jasa yang ada.

Selanjutnya adalah hasil pengujian hipotesis kelima $\left(\mathrm{H}_{5}\right)$ menunjukkan bahwa word of mouth dapat memediasi perceived price terhadap repurchase intention merek minuman Xing Fu Tang di Jakarta. Hasil ini menjelaskan bahwa hipotesis kelima tidak ditolak. Hasil penelitian ini sesuai dengan penelitian Moslehpour (2016) yang menyatakan bahwa word of mouth dapat menjadi mediasi antara variabel perceived price dengan repurchase intention. Dalam penelitian ini, dijelaskan bahwa word of mouth merupakan variabel mediasi dan memiliki pengaruh dalam mempengaruhi hubungan antara perceived price terhadap repurchase intention. Dengan adanya keyakinan bahwa produk Xing Fu Tang memang memiliki harga yang sesuai dengan kualitasnya maka akan menimbulkan niat konsumen yang pernah membeli untuk melakukan pembelian kembali minuman Xing Fu Tang.

\section{PENUTUP}

Dari berbagai hasil analisis yang sudah dilakukan pada bab sebelumnya, maka dapat ditarik kesimpulan perceived price dan country of origin tidak memiliki pengaruh positif dan signifikan terhadap repurchase intention. Variabel perceived price memiliki pengaruh yang positif dan signifikan terhadap word of mouth, sedangkan word of mouth memiliki pengaruh yang positif dan signifikan terhadap repurchase intention. Yang terakhir adalah variabel word of mouth dapat memediasi pengaruh perceived price terhadap repurchase intention.

Berdasarkan kesimpulan yang ada, maka peneliti memiliki beberapa saran untuk berbagai pihak terkait. Yang pertama, peneliti penyarankan pihak Xing Fu Tang untuk lebih mempertahankan produknya agar konsumen-konsumen yang sudah pernah membeli minuman Xing Fu Tang dapat terus memberikan informasi positif tentang minuman Xing Fu Tang. Apabila pihak Xing Fu Tang mampu menjaga informasi positif produknya, maka konsumen pun akan terus memiliki niat beli terhadap produk Xing Fu Tang. Yang kedua, peneliti juga 
menyarankan Xing Fu Tang untuk terus menjaga perceived price yang dimiliki konsumen terhadap produk-produk yang dimiliki Xing Fu Tang. Berdasarkan hasil analisis penelitian perceived price memiliki pengaruh yang cukup signifikan terhadap variabel mediasi word of mouth. Untuk penelitian selanjutnya, peneliti menyarankan untuk memperluas wilayah yang diteliti dan menambah jumlah responden yang diteliti agar penelitian selanjutnya dapat melengkapi penelitian sebelumnya dan lebih menggambarkan kondisi pasar yang ada.

\section{DAFTAR PUSTAKA}

Adekunle, S. A. \& Ejechi, J. O. (2018). Modelling repurchase intention among smartphones users in Nigeria. Journal of Modelling in Management, 13(4), 794-814.

Afsar, B. (2014). Effect of perceived Price, Brand Image, perceived Quality and Trust on Customer's buying Preference. Journal of Economics and Business Research, 20(1), 720.

Ajzen, I. (1991). The Theory of Planned Behavior. Organizational Behavior and Human Decision Processes, 50(2), 179-211.

Bahrinizadeh, M., Esmaiilpoor, M., \& Haraghi, M. (2014). Brand Equity and Country oTongf Origin Model in Pharmaceutical Industry. Journal of Business and Management, 3(6), 137-146.

Basil, G., Etuk, E. J., \& Ebitu, E. T. (2013). The Marketing Mix Element as Determinants of Consumer's Choice of Made-In-Nigeria Shoes in Cross River State. European Journal of Business and Management, 5(6), 141-147.

Choo, T. C., Jamil, B., Aryty, A., \& Daud, A. (2016). Electronic Word of Mouth on restaurants in Sarawak. Journal of Society and Space, 12(13), 39-49.

Chou, S. \& Chen, C. W. (2018). The influences of relational benefits on repurchase intention in service contexts: the roles of gratitude, trust and commitment. Journal of Business \& Industrial Marketing, 33(5), 680-692.

Diallo, M. F. (2012). Effects of Store Image and Store Brand Price-Image on Store Brand Purchase Intention: Application to an Emerging Market. Journal of Retailing and Consumer Services, 19, 360-367.

Ebrahim, R., Ghoneim, A., Irani, Z., \& Fan, Y. (2016). A brand preference and repurchase intention model: the role of consumer experience. Journal of Marketing Management, 32, 1230-1259.

Goh, S. K., Jiang, N., Hak, M. F. A., \& Tee, P. L. (2016). Determinants of Smartphone Repeat Purchase Intention among Malaysians: A Moderation Role of Social Influence and a Mediating Effect of Consumer Satisfaction. International Review of Management and Marketing, 6(4), 993-1004.

Hawkins, D. I., \& David, L. M. (2015). Consumer Behavior: Building Marketing Strategy. 13th Edition. Boston: McGraw-Hill.

Hellier, P. K., Geursen, G. M., Carr, R.A., \& Rickard, J.A. (2003). Customer repurchase intention: A general Structural Equation Model. European Journal of Marketing, 37 (11/12), 1762-1800.

Ibzan, E., Balarabe, F., \& Jakada, B. (2016). Consumer Satisfaction and Repurchase Intentions. Developing Country Studies, 6(2), 96-100.

Jimenez, N. \& Sonia, S. M. (2014). The central role of the reputation of country-of-origin firms in developing markets. Journal of Business \& Industrial Marketing, 31(3), 349-364.

Keni. \& Octaviani, W. (2018). Intergenerational Communication, Country of Origin dan Word of Mouth Untuk Memprediksi Ekuitas Merek. DeReMa Jurnal Manajemen, 13(2), 234245. 
Khan, M. S., Naumann, E., \& Williams, P. (2012). Identifying the Key Drivers of Customer Satisfaction and Repurchase Intentions: An Empirical Investigation of Japanese B2B Services. Journal of Contemporary Research in Business, 25, 159-178.

Kholid, M., Suharyono., \& Putra, A. S. U. (2016). Pengaruh Country of Origin dan Price terhadap Keputusan Pembelian. Jurnal Administrasi Bisnis, 40(2), 192-200.

Kim, D. J. (2012). An investigation of the effect of online consumer trust on expectation, satisfaction and postexpection. Information Systems and E-Business Management, 10(2), 219-240.

Latane, B. (1981). The psychology of social impact. American psychologist, 36(4), 343.

Maisam, S. \& Masha, R. D. (2016). Positive Word of Mouth Marketing: Explaining the Roles of Value Congruity and Brand Love. Journal of Competitiveness. 8(1), 19-37.

Matarazzo, M., Lanzilli, G., \& Resciniti, R. (2018). Acquirer's corporate reputation in crossborder acquisitions: the moderating effect of country image. Journal of Product \& brand Management, 27(7), 858-870.

Moslehpour, M., Wong, W. K., Pham, K. V., \& Aulia, C. K. (2016). Repurchase intention of Korean beauty products among Taiwanese consumers. Asia Pacific Journal of Marketing and Logistics, 29(3), 569-588.

Oosthuizen, D. \& Spowart, J. (2015). The relationship between perceived price and consumers' purchase intentions of private label wine brands. African Journal of Hospitality, Tourism and Leisure, 4(2), 1-17.

Phuong, N. N. D. \& Nguyen, T. D. (2017). The Effect of Country-of-Origin on Customer Repurchase Intention: A Study of Functional Products in Vietnam. Journal of Asian Finance, Economics and Business, 4(3), 75-83.

Pollack, B. L. (2017). Effects of exit barriers on word of mouth activities. Journal of Services Marketing, 31(6), 512-526.

Porral, C. C. \& Mangin, J. P. L. (2017). Store brand's purchase intention: Examining the role of perceived quality. European Research on Management and Business Economics, 23, 90-95.

Kumparan. (2019). "Rela Antre dari Setengah 5 Pagi di Grand Opening Xing Fu Tang Surabaya". https://kumparan.com/karjaid/rela-antre-dari-setengah-5-pagi-di-grandopening-xing-fu-tang-surabaya-1s5feKRTvF3/full

Saleem, M. A., Zahra, S., \& Yaseen, A. (2017). Impact of service quality and trust on repurchase intentions - the case of Pakistan airline industry. Asia Pacific Journal of Marketing and Logistics, 29(5), 1136-1159.

Suhaily, L. \& Soelasih, Y. (2017). What Effects Repurchase Intention of Online Shopping. International Business Research, 10(12), 113-122.

Suhud, U. \& Willson, G. (2019). Low-Cost Green Car Purchase Intention: Measuring the Role of Brand Image on Perceived Price and Quality. European Research Studies Journal, 22(3), 282-293.

Taghizadeh, H., Taghipourian, M. J., \& Khazaei, A. (2013). The Effect of Customer Satisfaction on Word of Mouth Communication. Research Journal of Applied Sciences, Engineering and Technology, 5(7), 2569-2575.

Thung, F. \& Leonnard. (2017). The Relationship of Service Quality, Word of Mouth, and Repurchase Intention In Online Transportation Services. Journal of Process Management. 5(4), 30-40.

Tong, C., Wong, A., \& Leung, S. (2013). The Mediating Effects of Service Charge Transparency on the Relationship between Corporate Social Responsibility and Customer Behavior in Hong Kong's Retail Banking Sector. Business and Economic Research, 3(1), 56-88. 